\title{
Problematizando a Gadamer
}

\section{Marif lor Aguilar}

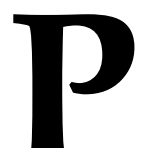

or doquiera resuena la propuesta hermenéutica de H. G. Gadamer entre otras cosas porque junto con Paul Ricoeur y Habermas es uno de quienes abanderaron la reivindicación contemporánea de la hermenéutica con éxitos definitivos; además, porque Gadamer recupera lo mejor de la tradición filosófica para proponer una teoría sumamente compleja y completa de la interpretación de textos, teoría que ha convertido a la hermenéutica en un supuesto obligado ${ }^{1}$ para todo analista o crítico social y literario en la medida en que toma sistemáticamente en cuenta la inmersión del sujeto y el objeto en sus contextos respectivos y extrae de esto sus implicaciones para el significado de la comprensión (verstehen). ${ }^{2}$

Mas no obstante el interés y relevancia del pensamiento gadameriano $-\mathrm{y}$ quizás precisamente por ello- vale la pena detectar ciertos puntos de fuga en algunos de sus planteamientos con el fin de poder echar mano de la mejor manera posible del aparato hermenéutico que ofrece. En lo que sigue haré una exposición medianamente detallada de la hermenéutica de Gadamer intercalando problematizaciones cuando se requiera. Esta exposición la dividiré en siete puntos. En el primer punto me referiré a la noción central de fusión de horizontes que representa un planteamiento epistemológico polémico en tanto plantea la relación sujeto-objeto como una identidad no hegeliana. La fusión de horizontes la relacionaré con las nociones de prejuicio, autoridad y tradición, centrales en el distanciamiento gadameriano de la Ilustración. En el segundo punto trataré la cuestión de la pertenencia del sujeto al proceso de producción de la verdad y de constitución del conocimiento mediante el procedimiento

${ }^{1}$ Una nueva Koiné dice Vattimo (Gianni Vattimo, Ética de la interpretación. Barcelona, Paidós Studio, 1991, p. 55).

2 J. Mendelson, "The Habermas-Gadamer Debate", en New German Critique, núm. 18 , otoño, 1979 , p. 51. 
dialógico. El punto siguiente, llamado "Dimensión práctica", alude a la naturaleza no sólo epistemológica de la hermenéutica. Después me referiré a una de las cuestiones centrales en el pensamiento gadameriano, a saber, la de la finitud. Aquí me referiré a cómo la finitud permite a Gadamer distanciarse de Hegel y, también, la importancia metodológica que puede tener la conciencia de tal finitud. En el quinto punto expongo algunos recursos filosóficos de Gadamer para sustraerse a planteamientos subjetivistas, y también esbozo algunas aporías que se derivan de tal estrategia. En el punto sobre la "aplicación" explico la relación de ésta y, por tanto de la interpretación, con el universo aristotélico de la práctica y de la phrónesis, lo cual hace entrar a los planteamientos hermenéuticos en conflicto con la teoría crítica y con ciertas tesis sobre la reflexividad. Por último, el séptimo punto está dedicado a la cuestión de la verdad y a plantear cómo esta noción, tomada de Heidegger, hace también entrar en conflicto los planteamientos gadamerianos con la crítica y la reflexión.

1o. Horizonte, prejuicio, autoridad y tradición. Entre el texto y el intérprete hay un horizonte común. El intérprete se acerca al texto sin abandonar su propio horizonte. A esto Gadamer le llama fusión de horizontes la cual supone una previa rehabilitación de las nociones de prejuicio autoridad y tradición fuertemente puestas en cuestión por la Ilustración. De lo que se trata en la situación hermenéutica es de obtener el horizonte correcto respecto de los objetos de la tradición que vamos a interpretar sin renunciar al horizonte que nos pertenece y desde el cual interpretamos. Desde mi punto de vista la tradición es un personaje central de la hermenéutica de Gadamer además de ser una vía para la crítica al subjetivismo. Es la tradición la que convalida las nociones previas que deberán incorporarse a la comprensión; es en la tradición donde debemos buscar las líneas de sentido que rebasan al individuo y que orientan la comprensión. ${ }^{3}$

La comprensión de un texto de la tradición no se lleva a cabo desplazándonos del todo, "por el contrario, uno tiene que tener siempre su horizonte para poder desplazarse a una situación cualquiera"; ${ }^{4}$ desde nuestro horizonte propio nos desplazamos hacia otro horizonte, con lo cual ascendemos "hacia una generalidad superior, que rebasa tanto la particularidad propia como la del otro". 5 La "fusión de horizontes" es importante para la comprensión porque hace explícita la tensión entre texto y presente, entre texto e intérprete, sin

${ }^{3}$ H. G. Gadamer, Verdad y método II. Salamanca, Ed. Sígueme, 1992, p. 262.

${ }^{4}$ H. G. Gadamer, Verdad y método I. Salamanca, Ed. Sígueme, 1991, p. 375.

${ }^{5}$ Idem. Más adelante dice Gadamer: "Una conciencia verdaderamente histórica aporta siempre su propio presente, y lo hace viéndose tanto a sí misma como a lo históricamente otro en sus verdaderas relaciones" (Ibid., p. 376). 
subordinar uno respecto del otro, ni reducir uno al otro. ${ }^{6}$

El que quiere comprender un texto también debe participar de los prejuicios que hicieron posible ese texto, debe comulgar con los valores y la cultura que conformaron las opiniones de la comunidad en la que se insertaba el autor de este texto. Es una cuestión de equidad: si nosotros proyectamos nuestros prejuicios, el texto tiene derecho también a proyectar los suyos propios.

De todos estos prejuicios, los del texto y los del intérprete, hay que saber distinguir los "buenos" de los "malos". Hay prejuicios legítimos que son los que hacen posible la comprensión, mientras que hay otros que la obstaculizan y producen los malos entendidos. ${ }^{7}$ La posibilidad de distinguir unos de otros descansa en la distancia en el tiempo que es tomada en cuenta aquí como una posibilidad positiva y productiva del comprender. ${ }^{8}$ Es la distancia en el tiempo la que instaura la dimensión crítica de la hermenéutica pues es la que elimina prejuicios inútiles y deja surgir otros que sí guían correctamente la comprensión.

En este punto se puede preguntar otra vez a Gadamer qué significa "guiar correctamente la comprensión", es decir, se puede preguntar otra vez por los criterios de validez o de legitimidad. Su respuesta aludiría a la durabilidad de los prejuicios, es decir, a la tradición. Por eso decíamos antes que es la tradición la vía regia para convalidar las propias opiniones previas así como una instancia en la que descansa el rechazo al subjetivismo, sólo los prejuicios que encuentran eco en la distancia temporal de la tradición serán sancionados. Anclar los prejuicios en la tradición y en la historia, lo hemos visto, aleja de la hermenéutica el fantasma subjetivista. Pero hay que preguntar si con esto quedan resueltos todos los problemas Ciertamente la respuesta es no. Resta resolver al menos el problema que se presenta cuando hay que elegir entre dos o más prejuicios, opuestos entre sí y arraigados en la misma tradición.

2o. Dialogicidad de la hermenéutica. La hermenéutica de Gadamer por otra parte, y por lo demás como toda hermenéutica al decir de Vattimo, "reivindica la pertenencia del 'sujeto' al juego de la comprensión y al evento de la verdad". ${ }^{9}$ Esta reivindicación del sujeto al "juego" de la comprensión y la verdad tiene lugar mediante la concepción dialógica de la interpretación. Entre el texto y el intérprete se establece un diálogo que parte de un acuerdo previo o precomprensión que se funda en la comunidad de lenguaje de la tradición del texto y del intérprete. En este sentido se trata de una comprensión abierta a la tradición.

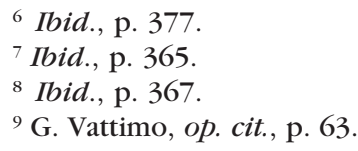


La comprensión tiene estructura de diálogo porque es el encuentro con la tradición, y ésta no es algo inerte sino que es lenguaje, "esto es, habla por sí misma como lo hace un tú". ${ }^{10} \mathrm{El}$ "tú" es un otro con el cual nos relacionamos pero que también tiene comportamientos respecto a uno. La conversación auténtica requiere también que se dé todo su peso al tú, es decir, "atender realmente al otro, dejar valer sus puntos de vista y ponerse en su lugar [...] querer entender lo que dice" recogiendo el derecho objetivo que tiene de expresar su opinión. ${ }^{11}$

Pero una buena conversación es aquella en la que los interlocutores saben preguntar. La comprensión hermenéutica comienza por la pregunta. Habíamos visto que el círculo hermenéutico comienza por saber escuchar lo que la cosa dice, pero este saber escuchar es posible si se sabe preguntar adecuadamente a la cosa. Preguntar quiere decir abrir; ${ }^{12}$ dejar "un abierto" sin respuesta predeterminada. La apertura está en una relación particular con la pregunta. Por un lado Gadamer afirma que la apertura (de la experiencia hermenéutica) tiene la estructura de la pregunta, pero por otro lado, sugiere que la apertura (el estar abierto) opera como criterio de validez o de legitimidad del preguntar: "decimos que una pregunta está mal planteada cuando no alcanza lo abierto sino que lo desplaza manteniendo falsos presupuestos". ${ }^{13}$

El recurso a la conversación tal como Gadamer la entiende como modelo de la comprensión hermenéutica es importante por diversas razones: primero, porque el modelo dialógico o conversacional representa un nuevo paradigma epistemológico que rompe con la concepción del conocimiento concebida como relación entre sujeto-objeto; segundo, resta peso al esencialismo metafísico pues enfatiza el preguntar por encima del responder; esto es que la pregunta hermenéutica es un preguntar en el sentido heideggeriano en tanto que no espera una respuesta sino apunta siempre a la dirección del preguntar; ${ }^{14}$ tercero, se opone al subjetivismo pues en el lenguaje en general y en su estructura dialógica rige la esfera del nosotros en lugar de la del yo. ${ }^{15}$

3o. Dimensión práctica. Son diversas e importantes las consecuencias de la concepción dialógica de la interpretación. Una de ellas es que en el proceso del diálogo ambos interlocutores se ven modificados. Mediante el acuerdo hermenéutico se lleva a cabo "una transformación hacia lo común, donde ya no se sigue siendo el que se era".${ }^{16}$ Lo que esto significa es que en el

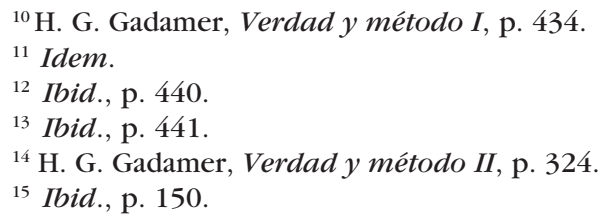


verdadero diálogo se lleva a cabo una transformación práctica de los que en él están involucrados. Estar-en-conversación es para Gadamer "salir de sí mismo, pensar con el otro y volver sobre sí mismo como otro". ${ }^{17}$

40. Finitud. Por otra parte, la comprensión hermenéutica que propone Gadamer está signada por la finitud, que se refiere a la imposibilidad de la completud del conocimiento por estar siempre atravesados por las ataduras al pasado, inaprehensible en su totalidad y presente siempre en la pertenencia y por las ataduras al futuro y su necesaria presencia en el proyectar,${ }^{18}$ la finitud tiene una doble connotación que no aparece claramente planteada. Por un lado alude a la dimensión histórica y temporal de la comprensión hermenéutica que se manifiesta en la "irrebasabilidad" de nuestra historia, es decir, en la imposibilidad de "superar", como quiso la filosofía moderna, aquéllo de lo que surgimos; pero por otro lado, y esto de manera no tan clara, alude a la imposibilidad del juicio racional basado en buenas razones y evidencias. Este segundo sentido de la finitud se detectará sobre todo en las respuestas de Gadamer ante los ataques de Habermas, pero también puede verse por sus efectos al posibilitar que se sustenten ciertas tesis en relación con la incuestionabilidad de la tradición.

La finitud es una categoría central de la hermenéutica de Gadamer ya que concentra su crítica específica al subjetivismo, al positivismo y al racionalismo de tipo hegeliano. Gadamer recuerda que no son Heidegger o Nietzsche los primeros en cuestionar la conciencia del sujeto y su certeza. Hegel desarrolla magistralmente la crítica y superación del espíritu subjetivo por el espíritu objetivo. El positivismo, por su parte, traza su proyecto teórico precisamente contra la participación de la subjetividad en la producción del conocimiento científico. ¿Cuál es entonces la diferencia entre ambas críticas a la conciencia? ¿Entre la crítica hegeliana o positivista y la heideggeriana o gadameriana? Esta diferencia se centra en la idea de la finitud. Hegel y el positivismo criticaron la subjetividad

${ }^{16}$ H. G. Gadamer, Verdad y método I, p. 458. Con esta idea de transformación, Gadamer continúa la idea heideggeriana de mudanza radical "del modo de ser del hombre en el mundo" mediante la superación de la metafísica. $C f$. G. Vattimo, op. cit., p. 125.

${ }^{17}$ H. G. Gadamer, Verdad y método I, p. 356.

${ }^{18}$ Queremos aclarar que aunque la noción de futuro es intrínseca al pensamiento heideggeriano y así debería serlo en el de Gadamer, en éste no es tan clara su presencia ya que aparentemente, en último análisis, la apertura intrínseca a la comprensión hermenéutica no es una apertura hacia el futuro como puede leerse en Heidegger, sino que puede -y quizá debe- leerse como una apertura hacia la tradición, o sea, otra vez hacia el pasado. Nuestra interpretación coincide con la de G. Vattimo quien afirma que "es posible sin embargo que la dirección en la que Gadamer retoma y desarrolla la ontología hermenéutica heideggeriana sea sobre todo la del pasado, lo cual entraña el riesgo de construir una especie de 'historicismo ontológico'” (G. Vattimo, $o p$. cit. p. 146). 
pero creyeron que dando un rodeo por el espíritu objetivo o por el método podía accederse a la transparencia de la conciencia. En la categoría de finitud lo que Gadamer con Heidegger postula es más bien la necesaria opacidad de la conciencia en cualquiera de sus formas incluyendo la conciencia científica.

Un plano relevante en el que se desarrolla la noción de finitud es mediante el término de "historia efectual" (Wirkungsgeschichte; literalmente: historia de los efectos). Lo que enfatiza la historia efectual es que la comprensión histórica es ella misma un efecto de la propia historia. Es decir, la historia efectual (o lo que es lo mismo: el principio según el cual la historicidad produce efectos sobre la propia comprensión histórica), determina nuestra selección de los temas históricos y de nuestro objeto de investigación. La historia efectual es, en este sentido, la conciencia de la historicidad de la propia comprensión histórica ("un pensamiento verdaderamente histórico tiene que ser capaz de pensar al mismo tiempo su propia historicidad"), ${ }^{19}$ y ésta consiste en la conciencia de la finitud. Es decir, no basta con saber que el proceso de la comprensión en general está atravesado por la historicidad, sino se requiere la conciencia de que el propio comprender comparte esta misma naturaleza y extraer de este hecho todas sus consecuencias, todos sus efectos. No es explícito Gadamer en este punto, pero lo que parece sugerir con la propuesta de la "conciencia de la historia efectual" es que la sola conciencia de la finitud, es decir, de la imposibilidad de abarcar todos los presupuestos de nuestro hacer y pensar, exige que tomemos distancia y relativicemos tales presupuestos.$^{20} \mathrm{La}$ investigación hermenéutica misma se ve modificada cuando el intérprete tiene conciencia de la finitud. Es decir, el intérprete tomará en cuenta la amplitud e infinitud del conjunto de determinaciones del texto y sabrá que su interpretación no puede abarcarlas todas, por lo que sus afirmaciones tendrán siempre el carácter de provisionalidad. La conciencia de la historia efectual impide asimismo elevarse por encima del propio condicionamiento. Abandonar la conciencia histórica es salirse reflexivamente de la relación vital con la tradición y quien hace esto, destruye el verdadero sentido de la misma tradición.

5o. Antisubjetivismo. Si el sujeto o intérprete está implicado en el comprender, esto no significa un rendimiento subjetivista, es decir, no significa que se sacrifica el objeto o la objetividad para concebir el conocimiento como un simple proyectar caprichoso; dice Gadamer siguiendo a Heidegger que el cono-

${ }^{19}$ H. G. Gadamer, Verdad y método I, p. 370.

${ }^{20}$ McCarthy atribuye esta lógica de pensamiento también a Rorty y la cuestiona ya que, plantea, la conciencia de la finitud o de nuestros presupuestos para hablar y actuar, más que para relativizar y tomar distancia de los presupuestos, deben servir mejor para construir un punto de partida de una pragmática reconstructiva. $C f$. Thomas McCarthy, D. C. Hoy, Critical Theory. Cambridge, Blackwell, p. 59, nota 29. 
cimiento no es un "proyectar planes, ni un extrapolar objetivos de la propia voluntad, ni un amañar las cosas según los deseos, prejuicios o sugerencias de los poderosos"; ${ }^{21}$ no, el conocimiento para Heidegger, es también acuerdo con la cosa; sólo que en este caso "la cosa" incluye también el proyecto, o como dice Gadamer, "la cosa" no es un "factum brutum, un simple dato simplemente constatable y medible, sino que es en definitiva algo cuyo modo de ser es el estar ahí",22 la proyección del intérprete hacia lo comprendido, confiere a "la cosa" la sustancia del ser-ahí, del ser humano. Siguiendo el pensamiento de Heidegger, lo que marca este "acuerdo con la cosa" es un principio de normatividad y de restricción de la subjetividad en la que consiste la libertad. ${ }^{23}$

Es para Gadamer importante dejar claro desde el comienzo de la exposición de su propuesta hermenéutica su rechazo al subjetivismo por lo cual emprende en esta parte una batalla campal contra las opiniones previas, las opiniones propias, nuestros hábitos lingüísticos, la "arbitrariedad de las opiniones previas inadecuadas”, etcétera. De éstas se proteje enfatizando a lo largo de toda su propuesta la exigencia de objetividad de la comprensión hermenéutica la cual se alcanza si el intérprete evita dirigirse hacia los textos directamente y, en lugar de esto, examina las opiniones previas, seleccionando las legítimas de las que no lo son. Las opiniones previas legítimas serán las que no desaparecen o no son aniquiladas por su origen y validez. En esta parte de la exposición Gadamer es crítico al hablar de la legitimidad de los prejuicios u opiniones previas. Aunque en ningún momento será suficientemente explícito, con desarrollos posteriores, que veremos enseguida, irán quedando más claros los criterios de validez o legitimidad a los que se refiere. Por ahora solamente ofrece algunas ideas como que la objetividad resulta de la convalidación que las opiniones previas van obteniendo a lo largo de su elaboración, ${ }^{24}$ o mediante el examen del intérprete de su origen y validez. ${ }^{25}$

En todo caso, no deja de representar un problema que Gadamer distinga las opiniones previas legítimas de las ilegítimas, al mismo tiempo que sostiene la tesis de la finitud en sus dos sentidos, como pertenencia a la tradición y como restricción cognoscitiva, pues si por principio la conciencia no es transparente para consigo misma, no se ve claro por qué puede serle transparente la legitimidad de unas opiniones previas y su diferencia de la ilegitimidad de otras. Lo que se puede anticipar como respuesta a esta cuestión es que en Gadamer la transparencia para la conciencia de la legitimidad o ilegitimidad de las opiniones

\footnotetext{
${ }^{21}$ H. G. Gadamer, Verdad y método I, p. 327.

${ }^{22}$ Idem.

${ }^{23}$ Cf. G. Vattimo, op. cit., pp. 70-71.

${ }^{24}$ H. G. Gadamer, Verdad y método I, p. 333.

${ }^{25}$ Ibid., p. 334.
} 
previas no es resultado de un acto reflexivo del sujeto sino de un obrar de la Verdad (alétheia) que hace posible que la legitimidad se haga patente revelándose.

6o. Aplicación. La fusión de horizontes se realiza en el momento de la aplicación. La aplicación constituye un momento polémico de la propuesta gadameriana que marca su especificidad pues lo que con él se propone es que sólo con la aplicación se efectúa la comprensión y la interpretación. La aplicación es el tercer momento de la unidad hermenéutica; el primero es la comprensión que en Gadamer significa comprender el mundo que el texto abre y no la subjetividad del autor; el segundo es la interpretación que significa hacer inteligibles en nuestro marco de referencia las creencias y prácticas que rodean al texto. El tercero es la aplicación. Lo que significa esta unidad hermenéutica es que la comprensión cambia con la situación concreta. ${ }^{26}$

La tesis de la aplicación polemiza con la hermenéutica tradicional que concebía separadamente este momento de los otros dos siguiendo la separación que habitualmente se plantea entre la teoría y la práctica: primero obtenemos la teoría y después la aplicamos en distintos momentos y lugares. Lo que Gadamer estaría planteando en cambio, es que la comprensión hermenéutica no crea una teoría abstracta aplicable a cualquier objeto y en cualquier momento posterior a su producción sino que es un tipo de comprensión más parecida al saber moral desarrollado por Aristóteles en la Ética a Nicómaco (phrónesis) que a la episteme, en tanto que ésta se puede pensar alejada del ser, mientras que el saber moral piensa la razón y el saber "no al margen del ser tal como ha llegado a ser sino desde su determinación y como determinación suya" ${ }^{27}$ Esta propuesta metodológica reúne categorías de un universo propio tales como "concreto", "práctica", "situación práctica", "situación concreta", etcétera, entrando en polémica con las categorías pertenecientes al mundo de los universales y, desde la óptica de McCarthy, también con el universo crítico ya que, según él, a partir de la noción de aplicación, la comprensión hermenéutica puede verse como la $\begin{array}{lllllllll}\text { e } & \mathbf{x} & \mathrm{i} & \mathrm{g} & \mathrm{e} & \mathrm{n} & \mathrm{c} & \mathrm{i} & \mathrm{a}\end{array}$ de encontrar suficientes puntos de referencia en el texto interpretado que lo hagan de interés para nuestro punto de vista lo que, a su vez, puede significar que deben reconocerse todas las pretensiones de validez planteadas por el texto. Esta lectura de McCarthy puede justificarse cuando leemos en Gadamer

${ }^{26}$ Dice Gadamer: "Si el texto, ley o mensaje de salvación ha de ser entendido adecuadamente, esto es, de acuerdo con las pretensiones que él mismo mantiene, debe ser comprendido en cada momento y en cada situación concreta de una manera nueva y distinta" (Ibid., p. 380). Sobre la relevancia de este momento hermenéutico, Cf. T. McCarthy, La teoría crítica de Jürgen Habermas. Madrid, Tecnos, 1987. The Critical Theory of Jürgen Habermas, 1978, y Joseph Bleicher, Contemporary hermeneutics. Londres, Routledge \& Kegan Paul. 
frases como la siguiente:"Uno tiene que dejar valer a la tradición en sus propias pretensiones, y no en el sentido de un mero reconocimiento de la alteridad del pasado sino en el de que ella tiene algo que decir [...] sólo nos conservamos abiertos realmente a la tradición si nos mantenemos abiertos a su pretensión de verdad". ${ }^{28}$ Esta frase podría leerse como afirmando dos cosas: o bien que todas las pretensiones de validez de la tradición son "dignas de diálogo" 29 o bien que todas deben ser aceptadas. Con afirmaciones como ésta Gadamer se pronuncia no solamente a favor de la inescapabilidad de la tradición sino aparentemente también a favor de su preeminencia cognoscitiva lo cual es inaceptable para los críticos ya que si se aceptara tal preeminencia se bloquea la posibilidad de poner en cuestión la tradición. El empeño de Gadamer -legítimo desde mi punto de vista- de no soslayar ni un solo aspecto de la historia y de la tradición en la comprensión hermenéutica lo conduce, aparentemente, a validar al mismo tiempo todas sus pretensiones de validez, lo cual puede significar -y aparentemente así es tomado por Gadamer- que se restringen las posibilidades de conocimiento diferentes a las postuladas por la tradición.

Según todo lo anterior el diálogo hermenéutico es un diálogo entre la tradición y su intérprete. La estructura de esta relación (entre tradición e intérprete) no es de naturaleza hegeliana con referencias teleológicas sino que tiene la naturaleza del acontecimiento, es decir, en ella "algo acontece". Ahora bien, la noción de "acontecer" continúa la lógica del combate al subjetivismo y al racionalismo pues alude al hecho de que no es el intérprete el que busca su objeto y "extrae" lo importante de lo dicho sino que, dejando al lenguaje como centro de la conversación y no a los interlocutores, la verdad acaece, se manifiesta, dejando surgir "algo que ninguno de los interlocutores abarcaría por sí solo".$^{30}$ La dialéctica que tiene al lenguaje como centro es el hacer de la cosa misma, que no es solamente experiencia del pensamiento como "del concepto que pretende liberarse por completo del poder del lenguaje", ${ }^{31}$ sino es un hacer de la cosa que es también un padecer, un comprender, un acontecer. Su diferencia básica con la dialéctica de Platón y Hegel es que éstas someten el lenguaje a su "enunciación", a lo- dicho, lo explícito, con lo cual el lenguaje no alcanza "la dimensión de la expresión lingüística del mundo". ${ }^{32}$ La dialéctica que corresponde a la experiencia hermenéutica concibe lo dicho en unidad de sentido con la infinitud de lo no-dicho. Esta dialéctica no es otra que la dialéctica de la pregunta y la respuesta, dialéctica que no une contrarios ni tiene principio y fin, ni telos ni Aufhebung; tiene sólo centro y este

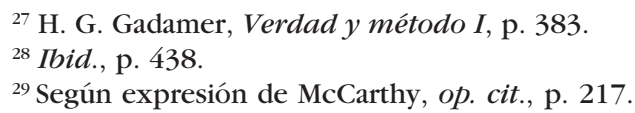


centro, que es la situación hermenéutica bajo la forma de la pregunta/respuesta, determina el "carácter interminablemente abierto del acontecer de sentido en el que participa". ${ }^{33}$ Ahora bien, la apertura del acontecer de la comprensión no significa su arbitrariedad. No toda comprensión es adecuada: "es el contenido mismo de la tradición el que proporciona el baremo único y el que se da a sí mismo acceso al lenguaje". ${ }^{34}$

Aparentemente, pues, "la cosa" no es más que el lenguaje de la tradición. Concluye Gadamer:

No es posible una conciencia en la que la "cosa" trasmitida pudiera aparecer a la luz de la eternidad. Toda apropiación de la tradición es histórica y distinta de las otras, y esto no quiere decir que cada una no sea más que una acepción distorsionada de aquélla: cada una es realmente la experiencia de un "aspecto" de la cosa misma. ${ }^{35}$

Me detendré aquí para hacer algunas observaciones. Cuando Gadamer opta para su hermenéutica por el modelo hegeliano de reintegración en contra del modelo reconstructivo de Schleiermaher, opta de hecho por la creación en contra de la recuperación de lo viejo. No se cansa de repetir a lo largo de su exposición que recuperar lo originario es imposible, bien sea el texto, la intención del autor, la pregunta a la que el texto responde, etcétera; siempre debe suponerse que no se recupera sino que se crea. Esto lo expresa, por ejemplo, en la frase que recién citamos que sugiere que siempre hay surgimiento de algo nuevo. Sin embargo, a pesar de tomas de postura y declaraciones en favor de la creación, creemos encontrar en el trabajo que hemos expuesto la presencia, en última instancia, de un elemento de pasividad reflexiva por parte del sujeto. Lo que no es extraño si consideramos que es precisamente el subjetivismo bajo la forma de la intencionalidad, uno de los enemigos filosóficos principales de nuestro autor. Según esto, la comprensión opera por "selección natural" de la historia y del tiempo: así se seleccionan los prejuicios, las opiniones previas y los propios textos que rompen la barrera de la distancia en el tiempo. Esta postura no deja de resonar al estructuralismo francés en sus diversas manifestaciones, con la salvedad de que para éste la lectura estructural de la realidad era ella misma producción del conocimiento, mientras que para

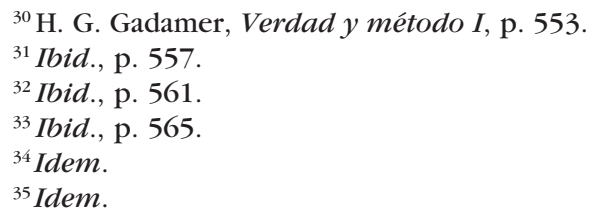


Gadamer aparentemente no es más que manifestación del ser.

7o. Universalidady verdad.$^{36}$ Gadamer cierra la exposición de su propuesta refiriéndose al aspecto universal de la hermenéutica. Una vez establecida la lingüisticidad de la mediación entre pasado y presente va a subrayar la universalidad: "la relación humana con el mundo es lingüística y por lo tanto comprensible en general y por principio".${ }^{37}$ Lo que quiere decir con esto es que todo aquello que tenga forma lingüistica es comprensible $y$, por tanto, objeto de la hermenéutica. Esta afirmación es importante por sus efectos entre los críticos, en particular en Habermas, quienes no están dispuestos a aceptar que la hermenéutica sea un instrumento suficiente para comprender ciertas manifestaciones lingüísticas como aquellas que están "distorsionadas" o infiltradas por los intereses o el poder. La tesis de la universalidad defiende que la hermenéutica está presente en todo comprender, científico y no científico y en ese sentido es anterior y más comprehensiva que la ciencia y sus métodos.

La experiencia hermenéutica es al final enmarcada por la noción de verdad como manifestación o revelación (alétheia). Para arribar a esta noción, Gadamer transita primero por el concepto metafísico de lo bello en cuya esencia está el manifestarse: "sólo a la belleza se le ha dado esto, el ser lo más patente y amable". ${ }^{39}$ De aquí se traslada a la metáfora de la luz para indicar que la manifestación o el aparecer es posible en virtud de su brillo, para luego llevar a cabo una equivalencia tendencial entre verdad y lenguaje, ya que previamente dirá que "la luz, que hace que las cosas aparezcan de manera que sean en sí mismas luminosas y comprensibles, es la luz de la palabra" ${ }^{40}$ Por último, explica la verdad en términos de juego para enfatizar el rasgo de la comprensión hermenéutica que da la espalda a la subjetividad y que entra en un espacio con reglas no establecidas por el intérprete.

Tal vez esta noción de verdad que esta a la base del pensamiento gadameriano es la que establece una limitante a la reflexividad del sujeto. Es la noción de verdad desarrollada por Heidegger según la cual se establece una equivalencia entre Lichtung y Wahrheit, entre el término Lichtung que apunta al despejamiento, al claro del bosque, y que a su vez es traducido como apertura por Vattimo, ${ }^{41}$ y la verdad. La Lichtung, según la lectura de Apel, no establece compromiso metodológico-normativo con aquello que se comprende; ${ }^{42}$ es simplemente el lugar abierto a la luz después de estar precedida por la oscuridad. La apertura del ser-ahí entendida en este sentido (como Lichtung) es un aconte-

${ }^{36}$ Agradezco a Luis Tamayo quien amablemente revisó esta sección y me hizo interesantes sugerencias.

${ }^{37}$ H. G. Gadamer, Verdad y método I, p. 568.

${ }^{38}$ Ibid., p. 574.

${ }^{39}$ Citado de Fedro, 250 d 7, en Ibid., p. 575. 
cer anónimo, condición de posibilidad de la constitución del sentido, que elude las cuestiones de la validez. La equivalencia entre la apertura (como Lichtung) que designa condiciones de posibilidad de la aparición del ente, y la verdad (que designa un compromiso valorativo), basculando el significado hacia el primer término y no hacia el segundo, hace que la noción de verdad sobre la que se asienta el pensamiento de Gadamer imprima a éste rasgos cuestionables por los críticos en tanto que esa noción de verdad (como manifestación) aparentemente no suscita la participación activa del sujeto quien ante la presencia develada de los entes pueda imprimir en ellos una direccionalidad.

Ahora bien, lo anterior no significa que no deban reconocerse los aspectos relevantes del ejercicio heideggeriano de identificar Lichtung y Wahrheit. Por el contrario, creo que la articulación de la verdad con Lichtung representa una revolución epistemológica pues apunta no sólo a los momentos luminosos de la producción del conocimiento (a la cadena sucesiva de verdades) sino a todo aquéllo que les antecede, a su historia, a sus condiciones de posibilidad, mostrando en ese movimiento que aquéllo de donde el conocimiento surge, habitualmente denominado error, no es más que un conjunto de "prejuicios tenaces solidarios" (Bachelard) que permanecen en la oscuridad. Por esto Lichtung conviene a la pretensión de pensar de otra manera la historia de la producción del saber, porque en tanto claro del bosque (o despejamiento) reúne en su seno tanto la claridad como la oscuridad, luz oscura ${ }^{43}$ que metafóricamente permite pensar lo no-pensado por la metafísica de la luz ${ }^{44} \mathrm{La}$ asimilación de alétheia a Lichtung, es decir de la verdad y el esclarecer, fuerza al pensamiento a pensar lo no-pensado, fuerza vincular el conocer con su historia y con sus "bajos fondos" (Nietzsche), radicaliza una postura frente a concepciones caducas de la producción de la ciencia. Esto es innegable e invaluable.

Pero como suele ocurrir, el precio que se pagó fue el de una reducción: en beneficio de la luz arrojada sobre alethéia, que no es otra cosa que el proceso de constitución del sentido, se eludió el compromiso de la fuerza reflexiva, es decir, la posibilidad de justificar o no las condiciones de posibilidad del comprender. ${ }^{45}$ La equivalencia entre Lichtung y Wahrheit representaría entonces algo que puede expresarse bajo la siguiente fórmula: una reducción y repliegue del momento de ilustración al horizonte del destino del ser que acontece. ${ }^{46}$

${ }^{40}$ H. G. Gadamer, Verdad y método I, p. 577.

${ }^{41}$ Siguiendo algunos pasajes de Heidegger en los que la apertura del ser ahí [Erschlossenheites] es llamada también Lichtung, según L. Amoroso, "La Lichtung de Heidegger como Lucus a (non) lucendo", en Gianni Vattimo y Pier Aldo Rovatti, $E l$ pensamiento débil. Madrid, Cátedra, p. 202.

${ }^{42}$ Karl Otto Apel, La transformación de la filosofía, t. I. Madrid, Taurus, 1985, p. 38 . 
${ }^{43}$ L. Amoroso, op. cit., p. 210.

${ }^{44}$ Ibid., p. 206. En relación con la Lichtung Heidegger habla también de "paraje" en tanto una "permanente extensión, que recogiendo toda la realidad, se abre de tal manera que, en ella, lo abierto es mantenido [gehalten] y empujado [angehalten] a dejar que surja cada cosa en su propia quietud", citado por L. Amoroso, Ibid., p. 206 de M. Heidegger, Gelassenheit.

${ }^{45}$ K. O. Apel, op. cit., p. 37. Vattimo se refiere también a esto en Ética de la interpretación: "[...] Una filosofía hermenéutica no puede nunca confundirse con una enésima 'descripción' de la estructura de la experiencia [...] La hermenéutica no puede dejar de comprometerse concretamente con la respuesta a la propia tradición y con el diálogo con las 'otras' tradiciones con que se mantiene en contacto. La hermenéutica no puede ser sólo teoría del diálogo, pues no se puede pensar efectivamente desde una teoría del diálogo (entendido como la verdadera estructura de toda experiencia humana), todavía 'metafísicamente' descrita en su esencia universal, sino que debe articularse, si quiere ser coherente, como diálogo, comprometiéndose, por tanto, concretamente, en relación con los contenidos de la tradición", ibid., pp. 66-67.

${ }^{46}$ Esta fórmula toma una idea de Apel en una paráfrasis nuestra de un pasaje de Habermas. La frase de Habermas es una crítica a Gadamer que sostiene que el descubrimiento de éste de que la comprensión se articula siempre a partir de prejuicios lo lleva a inferir una "reducción y repliegue del momento de ilustración al horizonte de las convicciones vigentes", en J. Habermas, La lógica de las ciencias sociales, Tecnos, p. 304. La idea de Apel va en la misma línea que hemos expuesto de su crítica a Heidegger en la que, cuestionando la separación entre constitución del sentido y validez, lo acusa de ser "una filosofía que, en definitiva, desearía derivar su propia legitimación del 'kairós' del destino del ser que acontece", en K. O. Apel, op. cit., p. 38. 